\title{
REALIDADES E INTERROGANTES DE UN HISPANISTA ANTE LA LLAMADA DAMA DE ELCHE
}

\author{
José Manuel Gómez-Tabanera \\ Universidad de Oviedo. España.
}

La presente Ponencia que se ofrece al I Congreso Internacional de Hispanistas, (Melilla, junio 1995), quizá pueda parecer extemporánea a algunos. No obstante, al aceptarse y consolidarse durante casi un siglo "la hispanidad" del busto estatuario conocido bajo el nombre de "la Dama de Elche", que ha llegado a ser tan popular y entrañable, en concretos niveles, como lo es para muchos la imagen de la Macarena sevillana; el mismísimo Pilar que realza a la imagen mariana de Zaragoza, o incluso la de la Santina de la cueva de Covadonga en Asturias, ha hecho que se trastoquen ideas harto caras a nuestra idiosincrasia, dado que nunca debe confundirse lo profano con Lo Sagrado... Esto no ha constituido obstáculo para que, con el paso de los años, más o menos inconscientemente, el icono/busto de la llamada Dama de Elche se haya convertido en el supuesto paradigma de la faz ideal de una muchacha española de mirada más bien triste e indefinida, con independencia de que hubiera podido vivir hace 2000 años en nuestra piel de toro, o hubiera podido ser contemporánea de la llorada diva andaluza Dolores Flores, primero "Lolita de Jerez", más tarde "Imperio de Jerez" y finalmente "Lola de España" o "la Faraona", desaparecida hace mes y medio, a los setenta y dos años y que, para muchos, ha pasado a ser una de las españolas emblemáticas de nuestro siglo.

Dos leyendas para dos mujeres. Sin embargo la cuestión a tratar aquí es otra, ya que prácticamente desde 1897, y a raíz de su hallazgo, la llamada Dama de Elche ha venido alimentando una leyenda singular o personal, tras 
ser considerada la imagen arquetípica de la hembra hispana de todos los tiempos, en su calidad de receptora, durante casi veinte lustros, de una serie de supuestos, inexactitudes, juicios e intuiciones que han venido elaborándose quizá, desde el mismo momento de la incorporación a la nuestra Historia de los llamados "iberos" a la vera de otros pobladores.

Todo esto ha venido acumulando, en el curso de prácticamente un siglo, una serie de despropósitos que, creo, va siendo hora de denunciar. El presente Congreso me parece pintiparado para ello tanto más, cuando no hay nada que cientificamente pueda oponerse al hecho de que la transida faz, un tanto hierática del busto inventado en Elche en 1897, pueda pertenecer lo mismo a un adolescente mediterráneo, norteafricano o ibérico de la Protohistoria, dentro de una cabal catalogación arqueológica, que, in extremis - como mantiene el especialista americano John Moffitt ' - , ser un triste fraude, que ha venido manteniéndose sin más, frente a los intereses de esa "hispanidad", que parece cristalizar entre modernismo y realismo, y las llamadas "Generación del 98" y "Generación del 14", a cuyo legado se debe la consagración del término y sus derivados.

\section{LA HISTORIA DE UN DESCUBRIMIENTO.}

Vayamos por partes. Nuestra exposición se remonta, ya lo hemos dicho, a 1897, y tiene como marco la localidad alicantina de Elche - la vieja Ilici-, mejor dicho, el lugar a unos 3 kilómetros de la misma, conocido como La Alcudia, una pequeña loma de diez hectáreas de superficie, situada en la Partida rural de Alzabaras Bajo, y a unos quinientos metros del Vinalapó, en el centro de la llanura que delimita al norte las sierras de Crevillente, Negra y Grosa, y en la que, en el curso de más de siglo y medio han venido produciéndose extraordinarios hallazgos arqueológicos, a datar a tiempos del dominio romano y púnico e incluso más atrás ${ }^{2}$.

En el año de referencia, La Alcudia venía a constituir un predio rural perteneciente al médico de Elche don Manuel Campello Antón, yerno del conocido hombre público y anticuario don Aureliano Ibarra Manzoni, (1834-1890). Quizá convenga puntualizar que La Alcudia nunca fue un latifundio del tipo evocado por nuestros más conspicuos regeneracionistas, aunque las circunstancia laborales de sus medieros y jornaleros, no eran, que duda cabe, las de hoy. Diremos no obstante que a la sazón, trabajaba en la finca, junto con otros, un joven jornalero, Manuel Campello Esclapez, del mismo nombre y primer apellido del amo, aunque sin relación familiar alguna con él. Es el mismo que, bastantes años después, dejaría constancia a un 
perdido e inolvidable amigo nuestro, don Alejandro Ramos Folqués ${ }^{3}$, que llegaría a ser propietario de lugar, como ocurrió el hallazgo del celebérrimo busto de Elche. Su declaración textual, recogida por el propio don Alejandro, será asimismo, años después, transcrita por el, también inolvidable, arqueólogo don Antonio García Bellido:

“...yo era entonces un muchacho de catorce años, por lo que no tenía edad para ir al jornal, pero ayudaba a mi padre y hermanos en las labores agrícolas. En el verano de 1897, se estaba nivelando la ladera del levante de La Alcudia para hacer bancales y en ellos plantar granados y alfalfa. En la fecha de referencia, o sea el cuatro de agosto, fui por la mañana a donde estaban los hombres trabajando, y serian las diez cuando los hombres, para descansar y fumar un cigarro, se fueron a la sombra de una higuera alli próxima; yo, mozalbete, mientras fumaban, cogí un pico y me puse a derribar el ribazo, y calcule usted mi asombro, cuando tropecé con una piedra que, al apartar la tierra para sacarla mostró el rostro de una figura. Llamé a los hombres, acudieron, y Antonio Maciá, de quien era la herramienta que utilicé, acabó de descubrir la Reina Mora, el busto estaba en posición normal, un poco inclinada hacia su derecha, mirando al Sudeste en dirección a Santa Pola; hallábase sobre dos losas de piedra de cantería, por delante cubierto de tierra, que se desprendió fácilmente del rostro y pecho y la espalda y los lados resguardados por losas iguales, a las que les servían de base, en número de seis, dos detrás y dos a cada lado. Nada más había alrededor, sino piedras irregulares y un trozo de pared. El hallazgo se comunicó inmediatamente al capataz, Antonio Galiana Sánchez, quien ordenó se dejase allí hasta que el doctor Campello al terminar su visita profesional, dispusiese de la figura" ${ }^{4}$

Tal es, literalmente, la evocación de don Alejandro Ramos, que recuerdo, nos resumió verbalmente - hace ya más de cuarenta años-, a un grupo de asistentes al III Congreso de Arqueología del Sudeste de España ${ }^{5}$, en una excursión a La Alcudia, en la que figuraban entre otros, si la memoria me es fiel, los finados Almirante Bastarreche, Presidente del Congreso; Julio Martínez Santaolalla, a la sazón Comisario General de Excavaciones; Antonio Beltrán Martínez, Conservador del Museo de Cartagena; el ingeniero Emeterio Cuadrado; Clarisa Millán, conservadora del M.A.N.; y el entonces joven historiador Jose María Blázquez... Quisiera recordar también, consultando viejas notas, como Ramos Folqués, nos señaló que el doctor Campello, dueño de la finca, sabía de sobra que en ella abundaban los restos arqueológicos ${ }^{6}$ y que siguiendo los deseos de su finado suegro, venía impartiendo instrucciones a sus jornaleros, para el caso de que encontrasen algún resto antiguo de interés. De aquí que, cuando la tarde del descubrimiento se presentó en La Alcudia, encontrase en cierto modo recompensados sus des- 
velos. Lleno de emoción, quiso hacer partícipe del hallazgo a todo el pueblo. Así que, ni corto ni perezoso, cargó el busto en el mismo carricoche que le había llevado a la finca y volvió con él a su casa de Elche. Allí y con objeto de que fuera inmediatamente conocido por todos sus conciudadanos y estos no le dieran la tabarra en los días subsiguientes, decidió exponerlo en un balcón de la fachada de su casa, frente a la que se dieron cita gran número de ilicitanos, desfilando bajo el balcón y haciendo los más curiosos comentarios en torno al hallazgo de La Reina Mora como, por consenso popular, fue bautizado de inmediato el busto - según nos relataría el cronista ocasional del suceso, don Pedro Ibarra, pariente del mismo médico —-. "Entonces, en pleno mediodía, bajo los ardientes rayos de un sol africano, viose grande y apretado grupo de gente que, atónitas, admiraban, desde la mitad de la calle la soberbia escultura, que, levantada sobre un taburete y recibiendo los rayos directos de aquel astro, que hacía veintidós siglos que no había acariciado su natural imagen, destacaba su imponente majestad, en el fondo oscuro del abierto balcón, cual si mágico conjuro hubiese evocado de los profundos abismos del pasado, el antiguo mito ilicitano".

De casa del médico sería llevado al siguiente día, al salón principal del Hotel de la Confianza, donde nuevamente pudieron admirarle nativos y forasteros, a la vez que, en el mismo, se hacían unas fotografías. Acto se devolvería el busto a la casa del médico.

Henos ante un acontecimiento que rompió la monotonía cotidiana de Elche y conmovió a todos los ilicitanos. Una semana después, cuando, al parecer por casualidad, pasó por Elche el arqueólogo francés Pierre París ${ }^{8}$, interesado en asistir a la tradicional representación del "Misterio de Elche" pudo saber del hallazgo con toda clase de pelos y señales, incluso con aditamentos peregrinos y fantasías. A este respecto el propio Pierre París recordaría: "en los casinos, en las tertulias diurnas, se cantaban las glorias del busto; en las casas, en las boticas, en los talleres, todos los obreros de alpargatas -es decir toda la población fabril del pueblo-, hablaban de él, al tiempo que insertaban las leznas en las suelas de esparto. Su fotografía brillaba en lugar preferente dentro del comedor del Hotel de la Confianza, honor supremo y suprema consagración. El busto se iba convirtiendo realmente en el idolo de la ciudad". Y he aquí, como, al parecer, Pierre París fue adquiriendo conciencia de la auténtica trascendencia arqueológica del descubrimiento y de la que no parecían aún haberse dado cuenta las gentes de Elche, incluido su afortunado propietario. De aquí que decidiera adquirirlo, fuera como fuera, para su patria, teniendo en cuenta por experiencias anteriores, que todo español parece siempre decidido a vender sus pertenencias, incluso por un precio irrisorio. La idea empezó a bullirle in mente y tras encargar una 
copia del daguerrotipo del busto, lo puso inmediatamente en el correo para París. Sucedió al mismo tiempo que Pedro Ibarra enviaba notas del descubrimiento a diversos círculos académicos de Londres y Berlín, pero también al Museo Arqueológico Nacional de Madrid, donde su Director no pareció interesarse demasiado por el descubrimiento ${ }^{10}$. No ocurriría así en Francia, donde alertados por Pierre París, desde Elche, las autoridades del Museo del Louvre, León Heuzey y Edmond Pottier "se dieron perfecta cuenta del interés del hallazgo y por telégrafo comunicaron a Pierre París que estaban dispuestos a comprar el busto por una cantidad que podría llegar hasta 4000 francos, que al cambio de entonces suponían unas 5200 pesetas. Cifra, a la sazón, considerable, más si se tiene en cuenta que, en monedas de oro, venían a ser 1040 gramos de oro de ley.

Disponiendo de tal baza, Pierre París pudo tentar al doctor Campello, que precisamente en aquellos días pasaba por una difícil prueba. El caso es que la gran colección arqueológica reunida por don Alejandro Ibarra, su suegro y legada a su única hija doña Asunción Ibarra Santamaría, había sido vendida a su muerte al M.A.N., que debía saldar su importe en tres plazos; los dos primeros habían sido ya abonados, pero no así el tercero, que en los mismos días del descubrimiento del busto de Elche no pudo hacer efectivo el doctor Campello, al serle protestado desde Madrid el pagaré correspondiente. Posiblemente fue por un error burocrático, pero el caso es que dicha devolución despertó la furia del médico, que ya tenía destinado el importe a recibir para el pago de unas tierras y tuvo que ingeniárselas, bien o mal, para atender a su compromiso. Lo más curioso es que Campello era un hombre de posición acomodada, que sabía bastante de arqueología por sus mismas relaciones familiares con su suegro y su cuñado, don Pedro Ibarra Ruiz, ("Perico"). Es lógico suponer que se encontrara ante un dilema y Pierre París no perdió el tiempo... Al parecer fue decisiva la opinión de la esposa del médico. El caso es que el 18 de agosto se cerró la venta del busto en la cifra ya mencionada de los 4000 francos. Sabemos algo más: el dinero fue adelantado por M. León París y al final la adquisición la pagó M. Noel Bardac.

Ya propietario legal de la escultura, Pierre París la embaló con todo cuidado en un cajón, utilizado algodón en rama. Doce días después, el mismo comprador, la trasladaría al puerto de Alicante, embarcando para Marsella a donde llegó después de tocar en Barcelona.

En París Noel Bardac, efectivo comprador del busto, hizo entrega of cial del mismo al Museo del Louvre, en calidad de donación. Allí fue instalado con todos los honores, en la sala Apadana del Departamento de Antigüedades Orientales, donde se expuso a partir de diciembre de 1897. 


\section{REACCIONES POSTERIORES HISPANAS Y RECUPERACION DEL BUSTO (1941).}

La reacción española ante la venta - para muchos vergonzoso expolio-, del busto de Elche a Francia, no se hizo esperar. Buena prueba de ello son las notas que el mismo día de cerrarse la operación escribió el tío político del vendedor don Pedro Ibarra Ruiz, ya recordado, a quien la transacción afectó profundamente. Rezan así: "18 de agosto de 1897. ¡Venta del Busto!, M. Pierre París, ha comprado para el Museo de Louvre el soberbio busto que posee Campello, hallado el día 4 en La Alcudia, por la suma de cuatro mil francos. No se lo que me pasa". Para escribir días más tarde: " 30 de agosto de 1897. ¡Adiós al Busto! - Hoy se ha llevado el busto M. París. ¿Y esto no tiene remedio? ¿Y no hay una ley en España que impida esto?. ¿Acaso porque un hombre no tenga afición a estas cosas no se le puede impedir, en nombre de la cultura pública, en nombre de la historia patria, cuya hermosa página debe ilustrar un día, no se le puede impedir el que venda ésta al extranjero?. ¿Qué dirán los amigos de Madrid del extranjero?, que yo no puedo evitar que salga el Busto de Madrid. Aún no me han contestado. Y Campello parece que tiene prisa para aprovechar la ocasión que, tan sin esperar, se ha presentado para vender el Busto".

Para mayor inri, la respuesta de don Juan de Dios de la Rada y Delgado ${ }^{12}$, entonces Director del M.A.N. debió de arribar al día siguiente de la transacción; pero en ella no se insinuaba adquisición por parte del Estado, ni oferta alguna. Solo proponía que se llevase el Busto a Madrid, donde sería examinado y valorado. Estaba visto que la supuesta máxima autoridad del Reino para decidir en el asunto - por lo menos a nivel oficial-, mostraba tan poco interés por el busto de Elche que ni siquiera intentó vetar la operación, por lo que el médico pudo cerrarla definitivamente. En realidad, muchas cosas, ayer como hoy, parecen no tener arreglo en nuestro país. Ahí estaba aún reciente el caso del via-crucis vivido por el santanderino Marcelino S. de Sautuola, a raíz de su descubrimiento del arte rupestre cuaternario contenido en la Cueva de Altamira ${ }^{13}$, ¡que distinto el comportamiento galo ante situaciones parejas!. No es de extrañar que La Reina Mora pasase a ser albergada, con todos los honores en el Louvre, a la vez que en España se labraba una fama a acrecentarse con los años. Pues el caso es que, desde su obligado exilio, empezó a hacerse popular, hasta el extremo de que prácticamente y durante casi medio siglo, a partir de la "Generación del 98", todo español un poco culto se preocuparía del "asunto pendiente" que significó su venta a Francia, tras su valoración como hito de un arte secular que solo empezaría a ser conocido y estudiado, en su auténtica dimensión, algún tiempo después ${ }^{14}$. 
Por otra parte, es significativo, que el nombre de Dama de Elche con que empieza a ser conocido el busto a nivel internacional, es traducción literal del que recibió tras su catalogación en Louvre. Ya hemos dicho que al busto, en Elche, obedeciendo quizá a un bautismo popular, más o menos instintivo o inconsciente, se le bautizó La Reina Mora, nombre que daba por sentado, "a primera vista", el presunto sexo del icono, al que incluso S. Reinach llamó Carmen, con el mismo nombre de la heroína de P. Merimé, al equipararla a una española que podía haber conocido Temistocles. La femineidad del busto, aceptada sin más, por el Louvre y sus autoridades, impediría cualquier duda al respecto, acallando desde un primer momento toda lucubración, que, no obstante, volverá a suscitarse en 1925 , tras un estudio, hoy clásico, del arqueólogo inglés Rhys Carpenter, al comparar sus proporciones con las del busto chipriota actualmente en el British Museun de Londres, conocido como el Apolo Chatsworth 's. El dilema apenas trascendió, más que para algunos enterados, y el caso es que la fama de la Dama de Elche fue afianzándose llegando a constituir una de las nostalgias del espanol culto en relación con otras obras trasterradas, como las mismas que hoy se exhiben en la Colección Wellington de Londres. Esto hizo que, en la primera mitad del siglo XX, se llevaran a cabo múltiples gestiones para traerla a Madrid, siquiera como depósito, sobre todo al quedar patente el papel secundario que parecía haber asumido en las salas del Louvre. Una de las primeras gestiones para su retorno se hizo bajo el reinado de S.M. Alfonso XIII, tras la inauguración de la Casa de Velázquez, (1928), residencia de artistas y becarios, sostenida por Francia, en la Ciudad Universitaria de Madrid. Perdida esta ocasión llegaría no obstante la definitiva ya en los inicios de la Segunda Guerra Mundial —verano de 1940 - a raíz de unas conversaciones entre las autoridades españolas y el gobierno de Francia, a la sazón invadida por Alemania y después de que la Dama de Elche, por razones de seguridad, hubiera sido trasladada, al castillo de Montauban, cerca de Toulouse. Fue entonces cuando, el gobierno del General Franco y el gobierno del Mariscal Petain, decidieron arreglar viejas diferencias, con el intercambio de obras expatriadas de antiguo, incluso desprendiéndose España, junto con otras francesas catalogadas en el Patrimonio Nacional. De esta forma pudieron retornar a España con el Busto, obras tan significativas como los relieves ibéricos de Osuna, el tesoro visigodo de Guarrazar ${ }^{16} \mathrm{y}$ alguna otra presea. El envío fue recibido con todos los honores a las 15 horas del 8 de febrero de 1941 en la frontera de Port-Bou, llegando a Madrid dos días después, a las 9:50 de la mañana, siendo trasladado e instalado, en parte, en el Museo del Prado. Allí permanecería instalada durante bastantes años la "Dama de 
Elche", hasta su traslado definitivo al M.A.N. donde hoy se exhibe junto con otras señeras muestras de la estatuaria ibérica ${ }^{17}$.

\section{PARA UNA PROGNOSIS DE LA LLAMADA "DAMA DE ELCHE”.}

Es lógico que el retorno de la Dama de Elche a la entonces España de Franco, llenó de satisfacción a muchas gentes bienintencionadas, que veían en ella "la esencia de Espańa" o "la caracterización definitiva de la mujer hispana", si nos atenemos a dos expresiones tópicas consagradas, que, más o menos, encierran una idea de autoafirmación altiva y exaltación de las propias raíces. Ello explica que el clímax suscitado hiciera posible la reproducción de su imagen en billetes de banco, sellos de correos y demás, al igual que ya había ocurrido con la imagen de Felipe II de Habsburgo y el monasterio de El Escorial, el pintor Francisco de Goya y su lúbrica maja o la mismísima carabela "Santa María" de la gesta colombina... Por otra parte, la Dama de Elche, sería reproducida para diversas marcas comerciales y establecimientos. Algo consustancial a la idiosincrasia hispánica, y que han puesto de relieve no solo sesudos tratadistas sino también críticos de otro talante tales como Luis Carandell y Francisco Umbral... La mass media hispana se encontraba pues ante un símbolo intocable, por lo menos hasta que especialistas como Gerard Nicolini, (1974), se atreviesen a poner en duda la autenticidad del busto, enfrentándose a la furia reaccionaria de la arqueología tradicional ${ }^{18}$.

En realidad mucho de lo que sucedería fue consecuencia obligada, más que de "una campaña judeo-masónica contra la España eterna", de los avances logrados en el campo de la investigación arqueológica y de la crítica de arte, a la vez que de un mejor conocimiento de las raíces étnicas de la Península Ibérica en muchas ocasiones un tanto opacas ante posiciones sectarias, fruto de un patrioterismo mal entendido o por una investigación lagunar, vergonzantemente conservadora.

Indudablemente la llamada Dama de Elche ha venido suscitado ingente bibliografía en los noventa y ocho años transcurridos desde su invención. Bibliografía de la que, tras recordar las publicaciones de P. París y J. R. Mélida, (1897), S. Reinach, (1898), Hübner, (1898), Ibarra, (1903), A. Schulten, (1920), J. Cabré, (1921), Sutherland, (1930) y alguno más, se tendrán en cuenta, casi totalmente, en el estudio de la escultura a publicar por A. García Bellido, (1943), motivado por su retorno a España ${ }^{19}$. Bibliografía que hoy, más de medio siglo después, se ha incrementado notablemente, sobre todo a partir de nuevos escritos del ya citado A. Ramos Folqués, (1945), y de su hijo Rafael Ramos Fernández, (1995), quien ha recogido la 
antorcha de la vocación familiar ${ }^{20}$. Pero también, del inolvidable A. Blanco Freijeiro, (1992), de uno del que suscribe, (1982), de la tesis doctoral/catálogo de Encarnación Ruano Ruiz, (1987), de J. Ma . Blázquez, (1987) ${ }^{21}$, y ya en nuestros días, tras la publicación, (1995), del tan provocador como interesante libro de John F. Moffitt, ya citado, y que considera a la Dama de Elche producto de un colosal fraude que se lleva a cabo hacia 1895, por obra de un escultor manierista no identificado, pero que acertó a recoger esencialmente en el busto, toda una serie de ideales impuestos por el arte simbolista occidental de fin du siècle ${ }^{22}$. Tesis ésta que parece avalar algunas de las lucubraciones de G. Nicolini, y que provocaría la airada respuesta de diversos especialistas españoles, aún antes de conocer el libro de $\mathrm{Moffitt}^{23}$, cuya publicación coincidirá, casi coetáneamente, con la de un ponderado trabajo del arqueólogo M. Bendala Galán ${ }^{24}$. De aquí que se imponga cierta cautela en nuestra posible prognosis.

Empezaremos recordando que es un busto tallado en piedra caliza, al parecer procedente de la cantera "Peligro", en El Ferriol, próxima a Elche. Sus dimensiones, $56 \mathrm{~cm}$. de altura, coinciden prácticamente con el tamaño real de la persona representada ${ }^{25}$. En la escultura se aprecian vestigios de policromía, particularmente en los labios, aún cuando de unos años a esta parte el color se ha venido apagando. Por el dorso, el busto presenta una gran oquedad irregular, hecha a propósito, sin motivación conocida, aún cuando cabe pensar que se ejecutase con fines litúrgicos, (guardar cenizas o reliquias, objetos sacros o benditos, etc), al igual que sucede con algunos iconos huecos, bustos-relicarios de plata, tallas de todos conocidas, etc. No hay indicio alguno, pese a que se ha insinuado, de que el busto, tal como ha llegado a nosotros, fuera parte de una estatua enteriza, rota en algún momento ${ }^{26}$, idea ésta que años atrás obsesionó al propio don Alejandro Ramos Folqués, quien en sus excavaciones en La Alcudia, no perdía la esperanza de encontrar fragmentos inferiores de la estatua o algo asimilable. Excavaciones muy fructíferas en otros sentidos, ya que permitirían encontrar diversa cerámica ibérica cuya temática pictórica y presunta datación ha originado hasta nuestros días diversos estudios ${ }^{27}$.

Allá por 1909 el historiador español don José Pijoan, en el Burlington Magazine desarrolló la idea de que el busto pudiera ser parte de un cuerpo entero parejo a "La Gran Oferente" del Cerro de los Santos ${ }^{28}$. La idea se desechó enseguida, pues aparte de que el estilo de ejecución del busto parece aproximarle más al estilo de los artífices del conjunto del Cerrillo Blanco de Porcuna, de clara influencia heládica ${ }^{29}$, la escultura ilicitana se aparta claramente del espíritu de la estatuaria del Cerro de los Santos y Llano de la Consolación, (Montealegre del Castillo, Albacete), y Osuna, (Sevilla) ${ }^{30}$, pero 
también de otro busto que ha llegado hasta nosotros muy deteriorado, conocido como Dama del Cabezo Lucero/Guardamar, Alicante ${ }^{31}$, restaurada un tanto arbitrariamente por Vicente Bernabeu Plaza, (1988), en un intento fallido de asemejarla a la estatua ilicitana, imitando su tocado y joyas, cuya consideración merece párrafo aparte.

\section{INTERROGANTES SOBRE UN TOCADO.}

El análisis del tocado del busto ilicitano ha venido constituyendo una de las bazas utilizadas por los distintos estudiosos del mismo para afirmar su femineidad, sobre todo a partir del hallazgo de la Dama de Baza en Cerro Mundi, Baza, Granada ${ }^{32}$ y otros de menor entidad ${ }^{33}$, que, a la larga han permitido afinar una posible periodificación del arte ibérico ${ }^{34}$. En los últimos años se ha intentado incluso reproducir la joyería del busto con trabajos de arqueología experimental que no han aclarado demasiado.

Por todo ello y con independencia de que el busto pudiera asimilarse a los maiorum de los romanos o a vasos-retratos, (kanopos), utilizados en el ámbito itálico y cuya función pudo haber sido conocida en el Sudeste de Hispania, merced a la corriente orientalizante que durante siglos conoció la Península, en su vertiente mediterránea, incluso imaginando una etapa "xoanica" ${ }^{35}$, ninguna causa objetiva parece explicar aún la presencia del recargado atavio en un busto/urna. Tengamos en cuenta que éste presenta tres collares que penden escalonados, sosteniendo una serie de pinjantes en forma de esencieros, plaquetas o conchas decoradas y glandes o bullas, que, en origen, tendrían que ser de metales preciosos y piedras finas. También cuentas, a elaborar quizá en pasta vítrea de distintas coloraciones. Aparte de todo esto, si nos detenemos a estudiar con detalle el busto, se presenta fuera de toda duda -independientemente de sus valores retratísticos-, que fuera cual fuese el sexo del joven representado, nos enfrentamos con algo diferente a toda la escultura ibérica: el tocado. Tocado que, nos permitimos señalar, no tiene parangón con ninguno de los que han llegado hasta nosotros desde la Protohistoria y Antigüedad, por su misma composición y simbolismo, que, hoy por hoy, no puede desentrañarse por mera comparación, al no conocerse, que sepamos, en todo el Mundo Antiguo, algo semejante o parecido ${ }^{36}$. Esto, de considerar genuino el busto, nos hace pensar en una presunta motivación, que no tiene nada que ver con el sexo de quien lo ostenta: el posible carácter sacro, simbólico o mágico del mismo, y que se considera digno de ser llevado por una divinidad bien notoria, que habria que identificar. De ser esta divinidad masculina, se nos ocurren dos nombres. Por un lado 
Triptolemo, cuyo culto sigue vigente en distintos ámbitos del Mediterráneo ${ }^{37}$; por otro, el mismo Helios/Apolo/Sol, antropomorfizado en alguna de sus epifanías, también vigentes en el ámbito mediterráneo orientalizante. En el caso concreto del busto ilicitano ¿̨orqué no puede ser el Apolo, tantas y tantas veces representado en una epifanía de singular belleza y visto como un kuroi inmarcesible y único?.

Precisamente en Elche podría justificarse su veneración y presencia, en virtud de la misma dialéctica de un rito incineratorio. De esta forma cabe pensar que la persona cuyas cenizas estaban destinadas a ser introducidas en el busto/urna, pudo conocer previamente el que podríamos denominar un último sacramento: "la solarización", que supondría su "fusión" con el astro diurno. Fusión ésta, que parece hacerse patente en la idealización del retrato/canopo, presentado con un particular tocado pleno de connotaciones "solares". Tocado ajustado en forma de tiara, cubriendo testa y orejas, y constituido por una especie de armadura en la que alguno ha pretendido ver un precedente de la "peineta", aún vigente en tocados femeninos tradicionales del Levante Español. Armadura que, por otra parte, se ha pretendido también ver cubierta por una "mantilla", que arranca de la misma frente, y cuyos bordes se presentan ocultos con una especie de diadema que ajusta o ciñe al tocado de forma particular y que, en la parte posterior de la cabeza, se hace estrecha, a la manera de una cinta conformada a la tiara. Esta diadema se ofrece ornamentada con diversos hilos en metal y engarces, y sirve de sostén, a cada lado de la cabeza, de sendos engarces de recorte eólico, que ajustan respectivamente a dos círculos o "rodetes auriculares", supuestamente en metal precioso, y en los que algunos tratadistas han pretendido ver uno de los más antiguos precedentes de los moños laterales del peinado femenino tradicional, ejecutados con trenzas de cabello enrolladas, junto a las sienes, y atravesadas con grandes alfileres o varillas ${ }^{38}$. Aquí y concretamente en el tocado que presenta el busto no hay rodetes ni moños capilares: son simplemente ruedas afianzadas merced a un doble tirante uniforme. Observamos asimismo que la cara interna de las ruedas presenta una decoración similar a la externa, con la excepción de dos especies de fíbulas o arracadas alargadas, coronadas por dos pares de volutas superpuestas de estilo eólico ya mencionadas y de las que cuelgan pequeños manojos de cordoncillos largos y flexibles, (ínfulas), terminadas en unas cabecillas o remates, que recuerdan a los que ostentan algunos torques áureos del NW. hispánico, como, pongamos por caso, el de Lanhoso, (Galicia).

Ambos simulacros auriculares - cuyo ancho canto presenta una decoración alternativa de flores de loto y triadas alineadas de semiesferas, parejas a las de la tiara-, no constituyen, en manera alguna, círculos completos, ya 
que en ambos es evidente una escotadura que rompe la totalidad circular, aproximadamente en unos $30^{\circ}$. Hecho éste, que nos ha hecho pensar, sin llegar a una respuesta en la misma escotadura que presentan ciertos escudos votivos, figurados en estelas funerarias extremeñas datadas en la Edad de Hierro ${ }^{39}$. El tocado se completa con una especie de toquilla o manto, que cubre hombros y espalda, y aparece cruzado en la zona pectoral, plegándose sus bordes a modo de ángulos escalonados, de la misma forma que aparece en la Dama de Baza y en esculturas del mundo griego. Finalmente, bajo el manto, que no cubre totalmente el busto, cruzan el pecho, desde el hombro izquierdo al costado derecho, una serie de pliegues sesgados que hacen pensar en una especie de chal, bajo el que asoma una túnica interior, ajustada a la zona del cuello, mediante una fíbula hispánica de un tipo catalogado.

A. García Bellido vio en el busto una cierta apariencia de corcova, que atribuyó al hecho, un tanto lógico de que el personaje figurado se presentaba bajo el peso de su tocado. Circunstancia ésta que se ha querido ver, negativamente, en otras figuras ibéricas, y que, en el modelo ejecutado hace ya años ${ }^{40}$ le daba, según Blanco Freijeiro, "aspecto de cantante de ópera entrada en carnes" 4 .

\section{ANTE UNA PRESUNTA SOLARIZACIÓN.}

Desde años atrás nos ha preocupado la semiótica del curioso tocado del busto de Elche, que se presenta harto diferente al que nos ofrecen otros simulacros del mundo ibérico, incluso refiriéndonos a horizontes anteriores, a situar en la Edad del Bronce y entre ellos, las figuraciones incisas que presentan ciertas estelas de significación funeraria, eco quizá de las estelas-ídolo, de la cultura megalítica occidental de la Península ${ }^{42}$. Henos ante una simbología que independientemente de su vinculación al mundo de la trasvida o de ultratumba, que inspira gran parte del mundo ibérico ${ }^{43}$, con las naturales "aculturaciones" y sincretismos, se nos ofrece con derivaciones particulares, de carácter mítico y ritual, entre las que cabe alentar una particular mitología a expresarse en epifanías diversas, desde iconos ocelados, en cierto modo sinecdoque del difunto, hasta otra semiología simbólica entre la que se encuentra el llamado "Carro del Sol", que transita diariamente en dirección Este-Oeste por el firmamento, confiriendo vida y calor al universo de sus creyentes y a la vez llevando las almas de sus muertos al Más Allá. Precisamente este viaje cotidiano de Febo se presenta recogido en Phaenomena, (vers.16211625) de R.F.AVIENO, dejando patente el hundimiento diario de el carro de Helios/Sol/Apolo en el mar de Calpe, seguido por una nube de fuego y en 
cuyos confines la mitología sitúa al Tártaro - nombre del que quizá surgió el de tartesos-y donde moran las almas de los decesos.

Esta presunta elaboración sigue perdurando en una época avanzada, en la que toda una sucesión de mitos parece mantenerse desde el Eneolítico, más o menos indemnes, metamorfoseándose o transformándose y expresándose en el llamado mito ctónico-solar desvelado hace más de un siglo por el historiador sevillano Alejandro Guichot y Sierra ${ }^{44},(1859-1941)$, y que se presenta mantenido por el dogma de la incineración de los difuntos, al objeto de facilitar su fusión en el Más Allá, con ese gran dispensador de la vida, que lo mismo puede ser Helios Apolo Psicopompo, que cualquier otra divinidad solar del mundo mediterráneo orientalizante. Esto puede explicar que el busto/canopo de Elche luzca tan singular tocado, en el que se presentan figurados más que los "ocelos" de la divinidad celeste - cuya faz a representar podría ser interpretada como una hipostasis de la diosa Tanit, (Dea Caelestis), con el deceso-, un presunto carro solar, figurado esquemáticamente mediante los disquetes que asume la faz del busto/canopo, independientemente del sexo del solarizado. Teorización ésta que nadie ha presentado hasta hoy, pero cuya posible confirmación está en la misma época, (siglos V-IV a.J.C.), en que pudo intentarse la instrumentalización del mito en un mundo orientalizante, en el que se han venido imponiendo las representaciones de carros, con significado cultual, incluso funerario, como el que asumen diversas urnas hallstáticas o se presenta en la mitología indo-irana, con sus Açvines o Dioscuros, divinidades que simbolizan la Luz, y que originariamente representaron al Sol y la Luna, hasta tornarse en la Estrella de la Mañana y la Estrella de la Tarde respectivamente. Leyenda en la que no faltan bellos caballos divinos que son sacrificados y ofrendados, como hipostasis de las mismas divinidades o sustituidos por figurillas votivas de équidos, (Cigarralejo, Murcia), a la vez que hace posible la presencia en distintas necrópolis ibéricas de carros cultuales.

\section{ANTE EL INTERROGANTE DE UN PRESUNTO FRAUDE.}

El asunto se ha mencionado anteriormente, de pasada. Es ahora el momento de plantearlo. Al parecer el busto de Elche, a raiz de las dudas expuestas por Nicolini alertó a más algún especialista que sabía de toda la serie de fraudes y engaños que había venido conociendo la Arqueología peninsular, a partir de sus primeros hallazgos de cierto valor material ${ }^{45}$.

En este sentido, el libro de John Moffitt constituye una summa de revelaciones, que terminan con la atribución de la autoría del busto ilicitano 
a un genial falsario de nombre Francisco Pallás y Puig, (Cuart de Poblet 1859 - Valencia 1926), cuya pericia como falsificador habla sido ya apuntada, en 1927, por don Manuel Gómez Moreno, tras el estudio de diversas obras en el campo de la eboraria mudéjar y gótica ${ }^{46}$, subrayando sus falsificaciones sobre materiales varios, (madera, marfil y piedra caliza). Al parecer Pallás se superó en falsificaciones sobre una especie de tuffo calcáreo bastante utilizado en el Levante y que, tras su extracción, podía esculpirse simplemente con una navaja.

Pallás se especializó en concretas obras ejecutadas en estilo mudéjar y gótico tardío. Llegó a un auténtico virtuosismo, hasta el punto de detallar arquetas, relicarios, (cofrecillos), en marfil de estilo arábigo y gótico, que vendía como auténticos a coleccionistas americanos ${ }^{47}$. Hay una serie de obras perdidas, hechas años antes de que, presuntamente, hiciera el busto de Elche. Precisamente en una de ellas ejecutada en marfil, el llamado Tríptico de la Virgen, hoy en la Walters Art Gallery de Baltimore, USA, en la parte superior del panel derecho, se figura un retrato de la reina Isabel I de Castilla, (1469-1504), que puede prefigurar el busto de Elche, si tenemos en cuenta los collares y tocado que presenta la soberana. Es muy posible que este retrato, más o menos ideal, inspirado a su vez en un óleo flamenco, fuese el presunto dechado del que partió Pallás para la ejecución del busto, usando de otros ornatos y collares, así como arracadas áureas en rueda e infulas que presenta, no solo la estatuaria femenina ibérica encontrada en el Cerro de Los Santos, sino también diversas figurillas votivas en bronce, o modeladas en barro e incluso esculpidas en arenisca ${ }^{48}$, que estudiaría Pallás.

Moffitt, en los capítulos 12 y 13, recrea el ambiente en que se forjó el fraude y que coincide con la emergencia del Modernismo en Occidente, que hará viable que se expresen diversos artistas, desde C. Brancusi a P. Picasso, pongamos por caso. A esta corriente artística que se inicia y que crea una moda y un estado de opinión, puede achacarse en parte el interés que el Louvre pudo tener en la adquisición de especímenes como este mismo busto de abigarrado tocado, hallado en un lugar recóndito de la España mediterránea y cuya posible compra ofreció el onnibulado París sin darse cuenta, como reconstruye minuciosamente Moffitt ${ }^{49}$, de que todo el affaire se le presentó preparado por dos inteligentes pillos, marginando al M.A.N. de Madrid, que, por lo visto, no podía atender a sus compromisos adquiridos.

La reconstrucción detectivesca de Moffitt se antoja aceptable, pero habría que presentar pruebas fehacientes de que los hechos sucedieron como sugiere, con independencia de que el busto fuera espúreo o no. Bastarla con probar que existió una relación previa entre Pallás y Campello, ya directa o antigua a través del finado, don Aureliano Ibarra, y que el falsario y el médi- 
co urdieron la trama con objeto de sacar al último de su compromiso económico. No obstante queda libre de toda sospecha la figura, más bien inane de Pedro Ibarra, a quien, al parecer, nadie hizo caso en M.A.N. de Madrid, al llover sobre mojado.

Cabe aquí cerrar el presente apartado, con la esperanza de que un conocimiento cabal por parte de nuestros estudiosos, de las tesis y aseveraciones novedosas de Moffitt, permita una revisión definitiva del busto, mediante análisis petrológicos de laboratorio y meteorización de la arenisca, espectrografía de pigmentos, búsqueda de nuevos items de comparación, etc, operaciones a las que solo puede procederse mediante las naturales autorizaciones, $\mathrm{y}$ tras los consiguientes impedimentos burocráticos. Y finalmente recalcar que si el fraude no fue descubierto en su día, se debe posiblemente al propio P. París, cuyo prestigio científico podría salir quebrantado, o al mismo "lobby" que gobernaba el Louvre y al que hubiera perjudicado seriamente un nuevo escándalo, tras el desvelado con la adquisición de la tiara de Saithafernes, joya falsa de presunto origen pontico ${ }^{50}$. Si alguien se barruntó algo lo silenció y la Dama conoció desde diciembre del 1897 un desfile de admiradores en el Museo del Louvre, mientras que España, en Guerra con los Estados Unidos, perdía los restos de su Imperio Colonial, a la vez que la llamada "Generación del 98" adquiría conciencia de los tiempos aciagos que vivían y de los que se intentará salir en los años venideros mirando hacia adelante y dando entrada al Modernismo y la adquisición de una nueva conciencia. Fruto de la misma, entre otros será el "noucentismo" catalán, que supuso adquisiciones expresiones teóricas y artísticas inéditas, como la Heliomaquía o "combate por la luz" de inspiración orsiana y de raíz griega", que se esforzaría por "descubrir lo que en nosotros hay de mediterráneo, y afirmarlo de cara al mundo y extenderlo, en obra imperial, entre los hombres". En manera alguna, con esta lucubración, que se afirmará bastantes años después en tesis nacionalistas fascistoides, autoriza a querer ver en el posible fraude de Elche arquetipos jungianos, a expresarse en la Diosa de Josep Clarà. Sin embargo, hemos de decirlo para justificar, en cierto modo, el anhelo que embargaría a las siguientes generaciones ilustradas hispanas, en el sentido de recuperar el busto de Elche convertido en emblemático, empenо que precisamente se logra bajo los auspicios de Franco.

\section{CONCLUSIÓN.}

Henos así, al final de un largo y pedregoso recorrido, entre realidades e interrogantes. Posiblemente nada mejor para imbuirse en el busto de Elche, 
que la descripción que del mismo nos dejó —entendida como divinidad, vestal o efebo-, A. Blanco Freijeiro ${ }^{52}$ quien, justo es decirlo, siempre abogó por su femineidad, al igual que A. García Bellido. Podemos aceptar ahora ésta, sin desdecirnos totalmente de conclusiones anteriores, a las que llegamos hace trece años ${ }^{53}$, barajando - de aceptar su genuineidad-, la posibilidad presentada por Bendala Galán ${ }^{54}$ de que el busto pudiera ser una "petrificación", (sic), de un icono femenino, esculpido en su origen en madera, al igual que las xoanas griegas y a las que la devoción popular - según heurística varia ${ }^{55}$-, gustaba de ornar con vestimentas, tocados, collares, arracadas, rodetes, peinetas y mantillas.

Una explicación aceptable, pero más bien conceptista para el caso del busto de Elche. De aquí que a nuestra lucubración anterior ya recordada nos permitamos añadir tres opciones, sin descartar la posibilidad de un fraude:

1. La Dama de Elche pudo ser sin más, y en su origen, un busto votivo destinado a guardar unas presuntas reliquias de la princesa Dido/Elissa, fundadora de Cartago ${ }^{56}$, que, de algún modo, llegaron a La Alcudia siendo objeto de veneración, tras su ubicación solemne en un rito de fundación. El busto/canopo, amortizado en tiempos posteriores, pudo ser incluido o escondido entre el material de las murallas del lugar.

2. La Dama de Elche puede ser considerada algo así como un excepcional legado de una religión mistérica, a extenderse incluso por el ámbito etrusco hacia el siglo $\mathrm{V}$ a.C., integrando cultos maternos de distinta entidad, (a Cibeles, Isis, Tanit Demeter, Ceres..), con ritos ctónico-funerarios en los que se utilizaba un carro cultual -el carro de Triptolemo-, cuyas ruedas asumían particulares simbolismos florales. Serán las mismas que aparecen figuradas como "rodetes auriculares" en el busto ilicitano".

3. La Dama de Elche es un busto de ejecución tardía ejecutado bajo el dominio romano, fruto de un culto mistérico local rendido a una divinidad materna y psicopompa que imponía a sus fieles particulares dogmas, algunos de ellos recordados en la decoración de la cerámica ibérica que diversas campañas arqueológicas vienen desvelando en La Alcudia de dos siglos a esta parte ${ }^{58}$.

Tenemos que concluir. Hacemos votos para que nuestra comunicación haya podido dar nueva luz sobre el busto de Elche, incluso dentro de la Weltschaunng orsiana que animó su formulación pugnando por la luz ${ }^{59}$ a la hora de abordar el "problema de España", aún sin resolver. 


\section{NOTAS}

1 JOHN MOFFITT, Art Forgery: The Case of the Lady of Elche. University Press of Florida, 1995.

2 Cf. RAFAEL RAMOS FERNANDEZ, El Elche de bace 2000 años. Ajuntament D'Elx, Col.lecció "Temes d'Elx" núm. XXII, 1994. En el mismo se contiene una sucinta bibliografia sobre la cuestión.

3 A. RAMOS FOLQUÉS La Dama de Elche, Madrid, Gráficas Uguina, 1945. La bibliografía ilicitana de A.R.F. llena casi sesenta afios y puede encontrarse totalmente relacionada en loc cit supra nota 2, pág. 85-89.

4 ANTONIO GARCLA BELLIDO La Dama de Elche $y$ el conjunto de piezas arqueologicas reingresadas en España, en 1941, Madrid, 1941.

5 La Historia de estas reuniones arqueológicas se presenta amenamente relatada en ANTONIO BELTRAN Ser Arqueólogo, Ed. Universidad y Empresa, Madrid, 1983

6 Precisamente Manuel Capello Anrón, yerno del acaudalado propietario del lugar, don Aureliano Ibarra y citular con su esposa del mismo, desde la muerte de su suegro, se sentía en cierto modo depositario del tesoro arqueológico que albergaba en su subsuelo que conoció diversas prospecciones, hasta que La Alcudia pasó a ser propiedad del mismo Alejandro Ramos Folqués.

7 Se trata de PEDRO IBARRA RUİZ, arqueólogo y cronista ilicitano que, tras cursar Bellas Artes en Barcelona, se diplomó en Archivos, Bibliotecas y Antigüedades, (1891). Ejerció de periodista, pero, asimismo, actuó de Facultativo de la Comisión de Monumentos de Alicante, impulsando la creación de su Museo provincial. Asimismo en 1890 promovió la Sociedad Arqueológica Ilicitana, de la que fue director. Fue correspondiente de la Academia de Historia, del Instituto Imperial de Berlín, a la vez que Cronista Honorario de Elche, prologando sus tareas hasta bien avanzado el siglo XX. En 1893, dio noticia de los hallazgos de las esfinges de Agost, en 1895 publicó su Historia de Elche. Su nombre se une, sin embargo, a la invención de "la Dama de Elche" que registra en Memoria bistórico-descriptiva del descubrimiento verificado en la zona de la Alcudia en la tarde del 4 de agosto de 1897, y que depositó en el Instituto General y Técnico de Alicante. El 10 de agosto notificó el descubrimiento a la Academia de la Historia de Madrid y a diversos estudiosos, pasando la noticia a Francia, Alemania e Inglaterra, y sufriendo particular decepción al ver que el Estado espaniol no le salía al paso al Museo de Louvre adquiriendo el busto ilicitano a sus parientes. Su actitud queda clara en su respuesta a El Pats de Madrid, 8 de noviembre de 1897, que, con el título "Sobre Arte Espafiol" contestó a una carta de Montemar, publicada a su vez en el Heraldo de Madrid con fecha 27 de octubre del mismo 1897. Pese a ello extrana que la Memoria de Ibarra nunca fuera publicada y que los círculos oficiales de Madrid, jamás comentasen su artículo, dando pábulo a la idea de que en el M.A.N. se pensase en un fraude, tras lo ocurrido en el Cerro de los Santos.

8 Hispanista francés y uno de los pioneros de la valoración del pasado arqueológico de España. Llegaria a nuestro país en 1895, por cuenta de la Academie des Inscriptions et Belles Letres, desarrollando una febril actividad durante un cuarto de siglo. Su intervención en la adquisición de La Dama de Elche por el Museo del Louvre de Parfs aparece muy bien pormenorizada en su obra Promenades Archéologiques en Espagne, (París, 1910). Fue autor del libro, hoy clásico, Essai sur l'Art et l'Industrie de l'Espagne Primitive, París, 1903-04, (Premio Martorell), primer mojón de la incipiente historiografia del Arte Antiguo de la Península y verdadero revulsivo para los primeros estudiosos nacionales. Director, desde su creación, del Bulletin Hispanique en 1899 y tras diversas actividades cientificas fue nombrado Director de la Ecole des Hautes Etudes Hispaniques de la Universidad de Burdeos, muriendo en Madrid en 1921, tras poner en marcha el proyecto de Fundación de la Casa de Velázquez, (1928).

9 Se trata de una celebración particular, supervivencia del teatro sacro medieval que viene celebrándose anualmente en la Basilica de Santa María de Elche, tras ser autorizada por un Prescripto 
papal de Urbano VIII. En dicha celebración mariana, cuyos orígenes se remontan quizá más allá del siglo XIII, (Misteri), se pasa revista al transito y coronación en los cielos de la Virgen María, urilizando para ello una imponente maquinaria que iza y baja una gran esfera que se abre en gajos, tomando la forma de una palmera y donde se alberga un ángel. En otros artefactos, también movidos por cuerdas, intervienen toda una serie de personajes bíblicos, vestidos ad hoc.

$10 \mathrm{Al}$ parecer se trataba de D. JUAN DE DIOS DE LA RADA Y DELGADO, quien entonces llevaba la dirección interina del M.A.N. y quien al parecer carecla de facultad de decisión para adquirit el busto, al que, no obstante, dedicará algún escrito dos afios después. De 1903 a 1905 tuvo que enfrentarse con el "affaire" de la autenticidad de la estatuaria hallada en el Cerro de los Santos.

11 A L. HEUZEI, Conservador del Departamento de Antigüedades Orientales del Louvre, se deben las primeras estimaciones en torno a la estatuaria ibérica. Es el mismo que patrocina las misiones de Arthur Engel a España, (1889), y poco tiempo después, de P. PARIS, que le informa puntualmente de novedades y descubrimientos. Precisamente al mismo, aparte de otros temas sobre el Arte Ibérico, se debe el articulo "Le buste d'Elche", Revue Encyclopedique VII, (1897), y "Le buste d'Elche et la missión de M.P. París en Espagne", CRAI, (1897).

12 Cf. supra nota 10.

13 Cf. J.M. GOMEZ-TABANERA, (Dir.) Altamira, Cumbre del Arte Prehistorico, Madrid, 1977. Quizá sea interesante recordar aquí, que el principal valedor de Sautuola fue el geólogo y catedrático Juan Vilanova y Pierá, quien sabemos que en mayo de 1891 se personó el Elche, acompafiado de don Juan de Dios Rada y Delgado, director del M.A.N. con objeto de ver y tasar la colección, (ibérica), de don Aureliano Ibarra, con vistas a su posible compra por el Estado.

14 Tendria que pasar, no obstante, bastante tiempo, para que, entre el cúmulo de bibliografla, más o menos dispersa, que irán auspiciando sucesivos descubrimientos, se disponga de un estudio pormenorizado del mismo, Arte Ibérico de A. GARClA BELLIDO, a incluirse en la monumental Historia de Espafia, (Dir. R. MENENDEZ PIDAL), en su como dedicado a la España prerromana, (I,3), págs. 371 y ss. Madrid, Espasa Calpe, 1954.

15 RHYS CARPENTER The Greeks in Spain, London, Longmans Green, (1925). En la misma se contiene una escala comparativa entre la cabeza del Apolo Chatsworth, hallado en Tamassus, Isla de Chipre y datado circa 460 a.C., y la de la Dama, ciertamente significativo y que deja en evidencia que ambas imágenes, independientemente de su sexo, se han hecho utilizando el mismo canon. Sobre el particular cf. asimismo John Moffitt Loc. cit. págs. 96-101, con atinadas glosas al estudio de Carpenter, en cierto modo parejas a otras nuestras de afios atrás, que no pueden echar en saco roto los defensores de la presunta femineidad del busto.

16 Se trata de una extraordinaria colección de coronas votivas visigodas, procedentes de Guarrazar, Toledo, y que hablan sido sacadas de la Península, en circunstancias nada claras. Su devolución había ya reclamada ardorosamente por el arqueólogo y erudito José Amador de los Ríos, desde el momento en que fue el primer tratadista que intentó confirmar la legitimidad de la monarquía espańola, vinculándola a la realeza visigoda, en la misma linea conceptual de la tesis defendida por SAAVEDRA FAJARDO, (siglo XVII), en su Corona Gótica.

17 Ello no es obstáculo, sin embargo, para que alguno de los items all exhibidos, se considere por algunos autores, de correcta filiación y de autenticidad probada, al igual que el busto de Elche.

18 G. NICOLINI, La Dame d'Elche: Question d'authenticité, Bulletín de la Societé Nationale des Antiquaires de France, abril, 1974, págs. 60-72.

19 Cf. supra nota 4

20 Es el mismo citado supra, nota 2. La aportación de R.R.F. a un mejor conocimiento del lugar viene incluida en la bibliografia citada supra nota 2, pág.. 82-85, a completar con Novedades escultórico-arquitectónicas en La Alcudia, REIb.1, págs. 107-114, Madrid, 1994.

21 A. BLANCO FREIJEIRO, Los Primeros Espanioles, Historias del Viejo Mundo, 1, Madrid, Historia 16, 1988; JOSE M. GOMEZ-TABANERA, Sobre contacto y cambio Cultural en el mundo iberi- 
co a la luz de La Antropologla, en Actas del VI Congreso Nacional de Arqueología, págs. 425-641, Zaragoza, 1983; ENCARNACION RUANO RUIZ, La Escultura Humana de Piedra en el Mundo Ibérico, Tesis mimeografiada, tomo I-II-II, Madrid, 1987; J.Ma. BLAZQUEZ, Historia de la Historiografia del Arte Iberico. Escultura y Bronces, en "Escultura Ibérica". Monográfico de Revista de Arqueología, págs. 20-31, Madrid 1987.

22 Cf. supra, nota 1. Las ideas a que me refiero aqul concretamente se exponen en el capítulo IX, págs. 114-139 del libro citado.

23 Algunas de ellas fueron publicadas en los diarios " $\mathrm{ABC}$ " y "El Pa/s" de Madrid, el pasado mes de marzo. La noticia del libro de Moffitt se publicó en marzo de 1995, coincidiendo con la celebración en Elche del XXIII Congreso Nacional de Arqueología, (8-11 de marzo), no dando apenas tiempo a que los especialistas reaccionasen, aunque dias después se expresasen con acrimonia sobre el particular los especialistas M. Almagro Gorbea, Alicia Rodero, Antonio Beltrán, Rafael Ramos y Manuel Bendala, que por estas fechas solo conocian la obra por una resefia enviada por fax, y el texto del prólogo al libro llevaba, firmado por J.A. Ramírez Domínguez, catedrático de Historia del Arte de la Universidad Autónoma de Madrid quien valoraba el esfuerzo de Moffitt. En los meses siguientes el libro en cuestión será silenciado e ignorado, hasta un posible pronunciamiento sobre el mismo del Ministerio de Cultura y su posible traducción en lengua espafiola.

24 CF. M. BENDALA GALAN, Reflexiones sobre La Dama de Elche, REIb.1, págs. 85-105, Madrid, 1994. Este artículo estaba ya impreso cuando se conoció en Madrid, marzo de 1995 la aparición del libro de J.Moffitt.

25 Cf. A. BLANCO FREIJEIRO, en Die Klassischen Wurzeln der iberischen Kunst, Madrider Mitteillungen 1, Madrid, 1960, describe asi el busto, "Dama de nariz larga y delgada de aletas breves: la boca, cuidadosamente modelada de labios finos, cerrados, herméticos. El ligero prognatismo de la mandrbula inferior, el pliegue vertical del labio superior y la ligera simetría del rostro, acaban de caracterizar y personalizar la expresión. Las mejillas enjutas dejan destacados los pómulos, dándole una delgadez casi ascética y hasta enfermiza. Su mirada parece abstraida en la contemplación vaga e inconsciente de algún punto cercano, a ello contribuye la posición de los párpados superiores que caen pesadamente sobre los ojos, disminuyendo su abertura e imprimiéndoles la mirada ligeramente vaga, esa expresión meditativa, absorta, estática..."

26 Ultimamente M. BENDALA GALAN en loc cit supra nota 24, pág.. 91, vuelve a plantear la posible rotura o seccionado traumático del busto, aunque descarta el hecho.

27 Entre estos y como más reciente aportación, cabe citar la cerámica que R. RAMOS presenta en El Templo Iberico de La Alcudia. La Dama de Elche. Ajuntament D’elx, 1995. Publicación presentada en el XXIII Congreso Nacional de Arqueologia.

28 Dicha estatua fue descubierta en 1870 y fue adquirida por Vives, apareciendo su primera mención en Memorias sobre las notables excavaciones bechas en el Cerro de los Santos publicadas por los PP. Escolapios de Yecla, Madrid, 1871, y su estudio ha venido originando ingente bibliografia.

29 Sobre la misma cf. J. GONZÁLEZ NAVARRETE, Escultura Ibérica de Cerrillo Blanco, Ed. Diput. Prov., Jaén, 1987, y T. CHAPA, "La Escultura Ibérica de Jaén en su Contexto mediterráneo, en Escultura Ibérica, Catálogo de la Exp. Mus. Prov. Jaén, Junta de Andalucía, Jaén 1990.

30 Sobre las mismas y su adecuación en su contexto cf. ROSARIO LUCAS PELLICER, Historiografia de la Escultura Iberica basta la Ley de 1911, I, REIb.1, págs. 15-42, 1994.

31 Cf. E LLOBREGAT y A. JODIN "La Dama del Cabezo Lucero, (Guardamar del Segura, Alicante)", en Saguntum, 23, págs 109-122, Alicante, 1990.

32 F.J. PRESEDO VELO, La Dama de Baza. Madrid, M.A.N. 1973.

33 M. RUIZ BREMON, "Los Exyotos del Santuario lbérico del Cerro de Los Santos", Antigüedad, Albacete, 1989 y también V.V.A.A. Salas de Antiguiedades Ibericas y Romanas, M.A.N., Madrid, 1980.

34 Cf. A. RUIZ y M. MOLINOS, Los Iberos. Andlisis Arqueológico de un Proceso Histórico, Crítica, Barcelona, 1993. De los mismos cf. el cuadro que se incluye en JAIME ALVAR, "De Argantonio 
a los Romanos. La Iberia Protohistórica”, en Historia de España 2. Historia 16/Temas de Hoy, Pág. 112, Madrid, 1995.

35 Me refiero al arte griego de los orígenes, con sus primeros iconos xilicos.

36 Quizá quepa hacerse una excepción recordando al viajero griego ARTEMIDORO, en cuya Geographoumena, (Libro II), recogido por ESTRABON en su Geographia, (3.4.17), recuerda unos ornamentos $y$ tocados bárbaros en bronce y hierro lucidas por las mujeres ibéricas, y entre los que no faltaban una especie de tocados cilindricos, (tímpanos), característicos, que no guardan parecido alguno con el que luce el busto de Elche, en el que, por otra parte, de ser obra de un falsario, habría que recordar los lucidos en bustos-relicario medievales de Nuremberg, circa 1400 , recogidos por JURGIS BALTRUSAITIS.

37 Se trata del "héroe cultural" que, en la mitología griega, por concesión de Demeter, cabalga en un carro alado por toda la Ecúmene, enseniando la agricultura a la Humanidad, iniciándola en los misterios de Eleusis.

38 Aún utilizados en tocados populares tradicionales de diversas regiones de la Península Ibérica.

39 Las mismas han sido objeto de particulares estudios, entre los que cabe recordar aquil los de $\mathrm{M}$. ALMAGRO BASCH, Las Estelas decoradas del Suroeste Peninsular, Bibliotheca Praehistórica Hispana 8, Madrid, 1966.

40 La reproducción en cuestión fue ejecutada por la Casa Carrera \& Carrera, joyerfa Madrilefia, bajo la dirección arqueológica de $M$. Bendala, Mónica Aparicio, Encarnación Ruano y M. Casamar, y el efecto logrado fue inenarrable. El maniquí, de coloración aleatoria, aparece fotografiado en $A$. BLANCO FREIJEIRO, Los Primeros Españoles, Historias del Viejo Mundo, 1, Historia 16, pág.. 74, Madrid, 1988.

41 Cf. A. BLANCO FREIJEIRO loc cit supra nota 40.

42 Sobre las mismas la bibliografia es harto extensa, debiendo tomar como punto de partida de la semiótica a considerar, el libro, ya clásico de O.G.S. CRAWFORD The Eye Goddess, Londres, 1957. También E. ANATI, Le Statue-Stele della Lunigiana, Jaca Book, Milán, 1981. En el mismo orden de ideas CF. J.M. GOMEZ-TABANERA, "EI Simbolismo funerario transcendente de los Ushabti nilóticos y de los denominados fdolos-Placa del Horizonte megalitista andaluz", en Actas del II Congreso de Historia de Andalucía. Prehistoria, págs. 147-166, Córdoba, 1991.

43 Solo citaremos un reciente trabajo sobre el tema R. SANZ GAMO y F.J. LOPEZ PRECIOSO, Las Necrópolis Ibéricas de Albacete. Nuevas aportaciones al Catálogo de Escultura Funeraria, REIb.1, págs. 203-246., Madrid, 1994.

44 A. GUICHOT Y SIERRA, El Mito chtónico-solar, Librerla de V. Suárez, Madrid, 1903.

45 M. RUIZ BREMON, "Las Falsificaciones del Cerro de Los Santos: Cuestiones de Actualización", Homenaje al Profesor Antonio Blanco Freijeiro, Págs. 131-161, Univ. Complutense, Madrid, 1989.

46 M. GOMEZ MORENO, "Los Marfiles Cordobeses y sus Derivaciones", Archivo Espaniol de Arte y Arqueologia, Págs. 233-243, Madrid, 1927.

47 Algunas de estas falsificaciones serfan denunciadas por A. GOLDSCHMIDT, "Pseudo-Gothic Spanish Triptychs of the Nineteenth-Century", Journal of the Walters Art Gallery, Baltimore, 1943.

48 Entre estas, asumen particular interés, un ex-voto en bronce procedente de Castellar de Santiesteban, representando a una mujer con un tocado en tímpano y portando grandes arracadas, $(12,3 \mathrm{~cm}$.); restos de una terracotta, (cabeza de $13 \mathrm{~cm}$.), de la Serreta de Alcoy y la pequeña estatua de una dama, (damita 7707), del Cerro de Los Santos, en piedra, $(29 \mathrm{~cm}$.), hoy en el M.A.N. y que en 1873 fue reproducida por P. SAVIRON Y ESTEBAN en su trabajo "Estatuas de piedra procedentes del Cerro de Los Santos", Revista de Archivos, Bibliotecas y Museos IV, 12, págs. 177-180, Madrid, 1873.

49 J. MOFFITT loc. cit. cap. 13, págs. 196-205. 
50 Sobre el "affaire" existe abundante bibliografia, independientemente de la evocación y resumen que del mismo hace el propio MOFFITT en su estudio. Cf. al respecto A. RIETH, Archaeological Fakes, (trad. inglesa del alemán), págs. 117-129, Barrie \& Jenkins, Londres, 1970. También RICHARD NEWNHAM, The Guinness Book of Fakes, Frauds of Forgeries, págs. 160 y ss. Londres, 1991. El falsario fue un tal Israel Rukhomovsky, (1860-1930), y el Louvre abonó por la tiara en 1896, nada menos que 200000 francos, es decir un $2000 \%$ de frs. más, que lo que costó el busto ilicitano un año después. El fraude de la tiara se descubrió en 1903, y si hubo sospechas sobre la Dama, no trascendieron, pues no se comentó nada cuando en 1940 se negoció el retorno del busto a la España de Franco.

51 Cf. al respecto JOSÉ LUIS ABELLAN, Historia Critica del Pensamiento Español VII. La Crisis Contempordnea II, (1875-1939), págs. 141 y ss., Circulo de Lectores, Barcelona, 1992. En la especulación de EUGENIO D'ORS, que va desde el catalanismo a la mediterraneidad, precedida de su Angeologia, se da una elaboración a culminar en La Bien Plantada, que, en cierto modo le hace imaginar, subconscientemente en pleno Modernismo/Noucentismo, a Lo Femenino en una imagen pareja a la de La Dama de Elche, aunque nunca la cite y que se devolverá a Esparia cuando, bajo el gobierno de Franco, cuando D'Ors es Jefe Nacional de Bellas Artes, y ha gestionado la devolución del tesoro del Museo del Prado, depositado en Ginebra.

52 El mismo BLANCO FREIJEIRO, loc cit supra nota 40.

53 Cf. loc cit supra nota 21.

54 Cf. loc cit supra nota 24.

55 Recordemos al respecto, como hace el mismo M. BENDALA GALAN, PAUSANIAS, Periegesis, (trad. de Antonio Tovar), 1946, donde se registran diversos simulacros que cumplian en las correspondientes ciudades griegas tal función, como imágenes de culto, a veces de materiales distintos, $\mathrm{e}$ incluso vestidas, cuando se trataba de imágenes femeninas. Podrían recordarse, no obstante, otras fuentes.

56 Hija del rey de Tiro, Bel, de donde tuvo que huir tras el asesinato de su esposo. Pudo llegar por mar, con sus fieles, a la costa tunecina, donde el rey Jarbas, de Zeugitania, le permitió asentarse en el terreno que pudiera abarcar la piel de un buey, a la que sagazmente la princesa redujo a tiras, uniéndolas, y pudiendo hacerse asl, con el suficiente terreno para construir la ciudadela de Byrsa, acrópolis de Cartago, (814 a.C.). Posteriormente Jarbas quiso hacerla su esposa, de acuerdo con la tradición, amenazándola con destruir la ciudad si se negaba. Heroicamente Dido se suicidó, arrojándose a una pira, y Cartago conmemoraria el hecho en los siglos siguientes, en su famoso Tophet, o templo sacrificial, excavado, no hace muchos años por P. Cintas. Es viable que cuando los púnicos se instalaron, tiempo después, en Iberia, portasen alguna reliquia, de Dido o que realizasen un sacrificio de fundación alli donde se asentaron. Elaboraciones posteriores, como Aeneidos del poeta romano VIRGILIO son históricamente ficcionales, pero ponen de manifiesto la fuerza de la tradición.

57 El simbolismo floral sigue siempre vivo en la religión ilicitana como parece demostrarlo diversa decoración de la cerámica ibérica e ibero-romana que vienen recogiéndose en La Alcudia, figurando también en ella presuntas imágenes angeliformes de Tanit y otras deidades veneradas en el lugar, perpetuando el mito de la Diosa Madre, en alguna de las manifestaciones recogidas por A. BARING y J. CASHFORD, The Myth of the Goddess, Arkana/Penguin, Londres, 1993.

58 Las últimas adquisiciones al respecto, han sido publicadas por R. RAMOS FERNANDEZ en $E l$ Templo Ibérico de La Alcudia. La Dama de Elche, cit, Elche, 1995, y en cuya segunda parte se intentan asociar los cultos ilicitanos a una potnia mediterránea, desarrollados de acuerdo con rituales particulares que intenta reconstruir mediante intuiciones/vivencias varias, inspiradas, en parte, por la interpretación, un tanto subjetiva de la documentación arqueológica.

59 Es la misma que inspirará con carácter aforismático y críptico, a EUGENIO D'Ors, pero también al presunto falsario, pero indiscutible artista, Pallás y Puig a la hora de dar rienda suelta a su creatividad mal entendida. 